\title{
Contribuição para 0 conhecimento dos LECITODENDRIIDAE do Brasil
}

por

\section{AURO TRAVASSOS}

(Com as estampas 24-26.).

A familia Lecithodendriidae é constituida por especies muito pequenas e difficeis de observar. Em uma nossa publicação anterior dividimos esta familia em duas subfamilias: Lecithodendriinae e Pleurogeninàe. Na primeira incluimos os generos Lecithodendrium, Paralecithodendrium e Acanthatrium; na segunda os generos Pleurogenes, Pleurogenoides, Limatulum, Loxogenes, Parabascus, Proso-

- tocus e Brandesia. O genero Phaneropsolus tinhamos, erradamente incluido entre os Brachycoelinae quando a situação delle é entre os Lecithodendriidae na subfamilia Pleurogeninae. A especie que descrevemos com o nome de Phaneropsolus mosesi deverá ser separada em genero a parte que denominamos Mosesia em homenagem a ARTHUR MOSES, com a seguinte diagnose: Lecithodendriidae; Pleurogeninae. Trematodeo pequeno, com cuticula guarnecida de espinhos; ventosa oral e acetabulum mais ou menos do mesmo tamanho; acetabulum pré-equatorial; pharinge em seguida a ventosa oral; cecos curtos e delgados; poro genital lateral, na zona acetabular, bolsa do cirrus em forma de virgula envolvendo o acetabulum, contem cirrus e volumosa vesicula seminal; testiculos equatoriaes, lobados, com zonas coincidindo e campos afastados; ovario parcialmente na zona testicular, lobado; espermateca presente; vitelinos extra-cecaes, pré-acetabulares; utero post-testicular; ovos pequenos.

Especie typo: Mosesia mosesi (TRAVASSOS, 1921).

Habitat: ? (Intestino de ave ?).

Aos Lecithodendrinae temos que acrescentar 3 especies novas para duas das quaes nos parece util a separação em genero a parte. Estas duas especies são muito affins e estavam parasitando o mesmo hospedador e muito se approximam do genero Paralecithodendrium; para este novo genero propomos a de- 
signação de Castroia em homenagem ao inegualavel miniaturista CASTRO SILVA a quem a parasitologia brasileira deve inestimaveis serviços.

\section{Castroia n. g.}

Lecithodendriidae - Lecithodendriinae. - Corpo reniforme, tendo muito maior largura que comprimento; acetabulum equatorial; testiculos com zonas coincidindo; ovario e acetabulum na zona testicular; cecos transversaes e não raro recurrentes; poro genital mediano, préacetabular; vesicula seminal enovelada e muito desenvolvida e ao lado do acetabulum; testiculos transversalmente alongados; ovario lobado; vitelinos extracecaes, pré-testiculares, anteriores; utero com alças transversaes.

Especie typo: Castroia silvai $n$. $s p$.

Habilat: Intestino delgado de Chiropteros.

Além da especie typo incluimos no mesmo genero outra especie que denominamos C. amplicava.

Este genero se approxima de Paralecithodendrium do qual se distingue pelo maior desenvolvimento lateral que dá ao trematodeo um facies peculiar, além disto a vesicula seminal, ovario, testiculos e acetabulum ficam numa mesma zona mas sem superposição de areas.

\section{Castroia silvai n. $s p$}

(Fig. 1-3)

Trematodeo pequeno, reniforme, com largura muito maior que o comprimento e não raro com uma curvatura de concavidade anterior. Medem 0,84 a $1 \mathrm{~mm}$. de comprimento por 1,2 a $1,5 \mathrm{~mm}$. de largura maxima; acetabulum mais ou menos igual a ventosa oral, equatorial, mede cerca de 0,078 a $0,085 \mathrm{~mm}$. de diametro, dista 0,24 a $0,30 \mathrm{~mm}$. da ventosa oral; ventosa oral terminal, com cerca de 0,085 a $0,100 \mathrm{~mm}$. de diametro; pharinge logo em seguida a ventosa oral com cerca de 0,028 a $0,035 \mathrm{~mm}$. de diametro; esophago curto, mede cerca de
0,085 a $0,143 \mathrm{~mm}$. de comprimento conforme a distensão do corpo do parasito; recos transversaes, quasi $\mathrm{em}$ angulo recto com o esophago, delgados, medem cerca de 0,44 a $0,55 \mathrm{~mm}$. de comprimento; poro genital mediano, logo acima do acetabulum; vesicula seminal muito desenvolvida e enovelada, sem bolsa do cirrus, fica situada ao lado do acetabuIum em semitria com o ovario: testiculos alongados transversalmente e lobados, abaixo dos cecos, com zonas coincidindo e campos muito afastados, equatoriaes, medem cerca de 0,21 a $0,35 \mathrm{~mm}$. de maior diametro por 0,10 a $0,15 \mathrm{~mm}$. de diametro transversal; ovario lobado profundamente, com 4 a 6 lobos, na zona testicular e com o campo em contacto com o campo de um dos testiculos, em opposição a vesicula seminal, mede cerca de 0,21 a 0,27 por 0,11 a $0,17 \mathrm{~mm}$.; glandula de Mehlis na zona ovariana, entre o ovario e o acetabulum; canal de Laurer presente, lateral, mais ou menos na area da glandula de Mehlis; espermateca não foi observada; vitelinos pré-testiculares e pré-cecaes, nos campos dos testiculos, são constituidos por folliculos grandes e pouco numerosos; utero com alças transversaes sendo as alças anteriores cheias de ovos maduros e de casca escura; ovos de casca espessa e de côr castanho escura quando maduros, medem cerca de 0,019 a $0,020 \mathrm{~mm}$. de comprimento por 0,010 a 0,011 de maior largura; a vesicula excretora não poude ser observada com nitidez.

Habitat: Intestino delgado de Peropteryx canina WIED.

Proveniencia: Angra dos Reis, Estado do Rio (Necropsia no 4.301).

o nome da especie foi tambem dado em homenagem a CASTRO SILVA.

\section{Castroia amplicava n. sp.} (Fig. 4-6).

Corpo reniforme, formando uma curvatura de concavidade anterior e um sulco no meio da porção posterior (su- 
perficie convexa) no fundo do qual se abre o poro excretor. Mede cerca de 0,84 a $0,92 \mathrm{~mm}$. de comprimento por uma largura de 0,95 a $1,5 \mathrm{~mm}$; acetabulum maior que a ventosa oral, equatorial, a $0,24 \mathrm{~mm}$. da ventosa oral e com cerca de 0,15 a $0,17 \mathrm{~mm}$. de diametro; ventosa oral terminal com cerca de 0,071 a 0,085 $\mathrm{mm}$. de diametro; pharinge em seguida a ventosa oral e com cerca de $0,42 \mathrm{~mm}$. de diametro; esophago com 0,085 a 0,114 $\mathrm{mm}$. de comprimento; cecos divergentes, transversaes, quasi normaes a direcção do esophago e as vezes mesmo recurrentes, medem cerca de 0,54 a $0,61 \mathrm{~mm}$. de comprimento; poro genital mediano, logo acima do acetabulum; vesicula seminal ao lado do acetabulum, em simetria com o ovario, sem bolsa do cirrus; testiculos alongados no sentido transversal de contorno regular ou ligeiramente lobados, zonas coincidindo e campos affastados, na zona acetabular, medem cerca de 0,21 a $0,28 \mathrm{~mm}$. de comprimento por 0,12 a $0,21 \mathrm{~mm}$. de maior largura; ovario profundamente lobado, na zona testicular e com campo em contacto ao campo de um dos testiculos, mede cerca de 0,24 a 0,27 por $0,14 \mathrm{~mm}$. de diametro transversal e longitudinal; glandulas de Mehlis na zona ovariana, entre o ovario e o acetabulum; canal de Laurer lateral, mais ou menos na area da glandula de Mehlis; vitelinos extracecaes, pré-testiculares, nos campos testiculares e constituidos por folliculos volumosos e em pequeno numero, viteloductos cruzando de um lado o ovario e de outro a vesicula seminal e passando por traz do acetabulum; utero constituido por alças transversaes das quaes as anteriores encerram ovos maduros; ovos de casca espessa e de côr castanho escuro, medem cerca de 0,019 a $0,020 \mathrm{~mm}$. de comprimento por 0,010 a $0,011 \mathrm{~mm}$. de maior largura.

Habitat: Intestino delgado de Peropleryx canina WIED.
Proveniencia: Angra dos Reis-Es tado do Rio (Necropsia no 4.304).

Esta especie é muito proxima da precedente com ella se confundindo, distingue-se principalmente pelas dimensões do acetabulum, maior que a ventosa oral e pelo sulco da extremidade posterior; os vitelinos tambem são constituidos por menor numero de folliculos que são mais volumosos e os testiculos são em geral de contorno mais regular.

Paralecithodendrium liliputianum $n . s p$. (Fig. 7-8)

Parasito de dimensões muito redusidas e muito difficil de observar, de corpo piriforme; mede cerca de 0,28 a $0,29 \mathrm{~mm}$. de comprimento por uma largura de 0,17 a $0,20 \mathrm{~mm}$; ventosas relativamente grandes medindo o acetabulum cerca de $0,11 \mathrm{~mm}$. de diametro, equatorial, a cerca de 0,032 a $0,040 \mathrm{~mm}$. do rebordo posterior da ventosa oral; ventosa oral sub-terminal, com cerca de 0,080 a $0,088 \mathrm{~mm}$. de diametro; pharinge não poude ser observado; cecos transversaes, muito curtos; poro genital préacetabular, mediano; vesicula seminal grande, obliqua, na zona e as vezes na area acetabular; testiculos com zonas coincidindo e coincidindo parcialmente com a zona acetabular, campos afastados, de forma redonda e de contorno regular, medem mais ou menos $1 / 3$ a $1 / 2$ do diametro acetabular; ovario post-testicular com zona coincidindo parcialmente com a zona testicular e em contacto com a zona acetabular, campo afastado dos campos testiculares mais coincidindo com o campo acetabular; a glandula de Mehlis não poude ser observada; vitelinos mal visiveis, pré-acetabulares, na zona da ventosa oral e no campo dos testiculos; utero muito desenvolvido occupando quasi todo o corpo do parasito; ovos relativamente muito grandes, de casca espessa e de côr amarello castanho, medem cerca de 0,029 a 
$0,032 \mathrm{~mm}$. de comprimento por 0,016 a $0,018 \mathrm{~mm}$. de maior largura.

Habitat: Intestino delgado de Peropteryx canina WIED.

Proveniencia: Angra dos Reis Estado do Rio (Necropsia no 4.304).
Esta especie encontramos reunida ás duas outras. Approxima-se do P. cordiforme do qual se distingue pelo tamanho total e pelas dimensões relativas das ventosas. 
EXPHCAGÃO DAS ESTAMPAS 24-26.

Fig. 1-2 Esquema de Castroia silvai. Fig. 3-4 Castroia silvai.
Fig. 5- Esquema de Castroia amplicava Fig. 6-7 Casiroia amplicava.

Fig. 8-9 Paralecithodendrium liliputianum. 


\section{BIBLIOGRAPHIA}

TRAVASSOS, L. 1921. Contribuição para o conhecimento da fauna helmintolojica brasileira XI. Sobre as especies brasileiras da familia Lecithodendriidae. Arch. Esc. Sup. de Agricultura e Med. Veterinaria V. 5 , no $1-2$, p. 73 . 


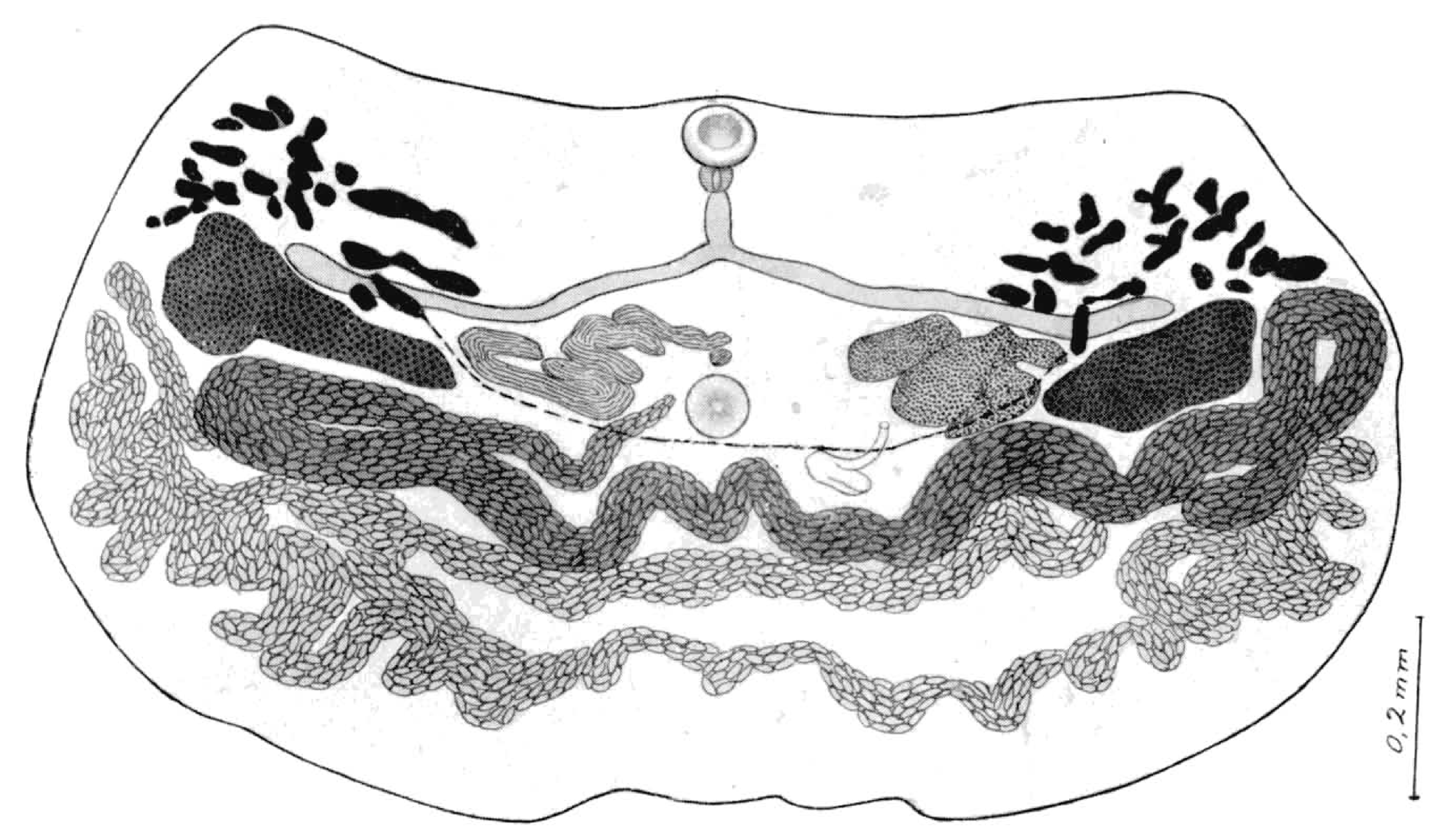

Fig. 3

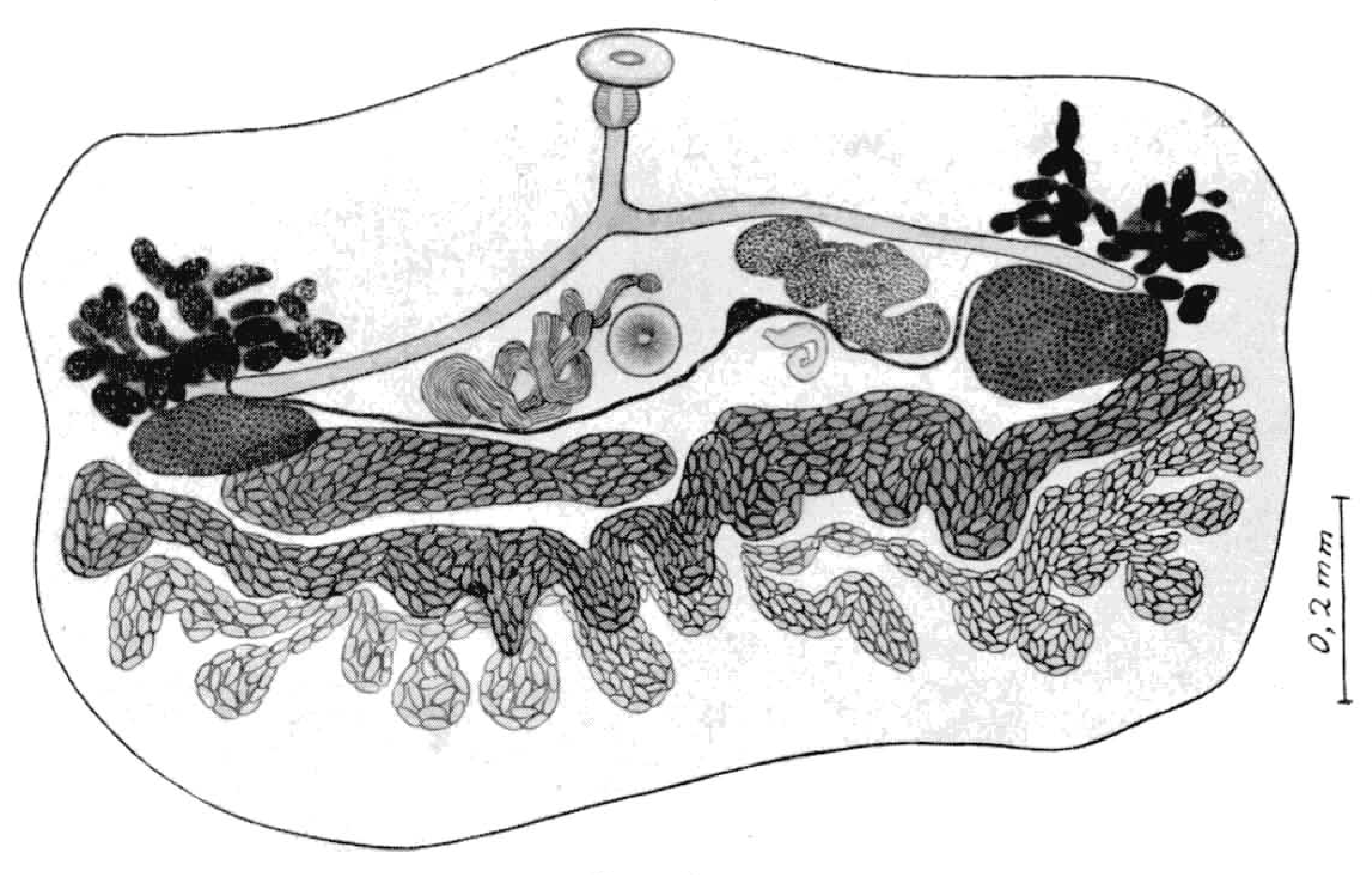

Fig. 4 


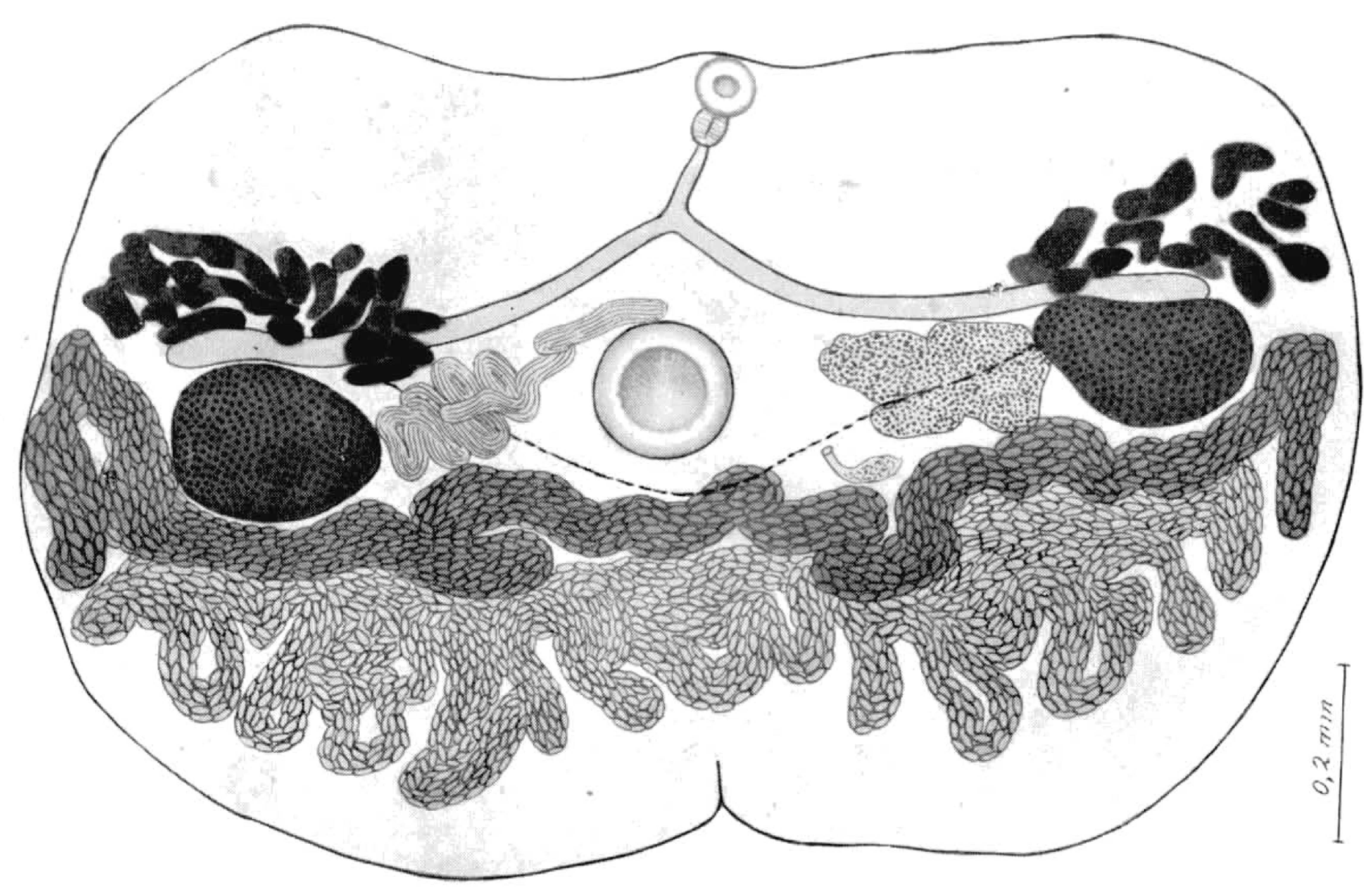

Fig. 6

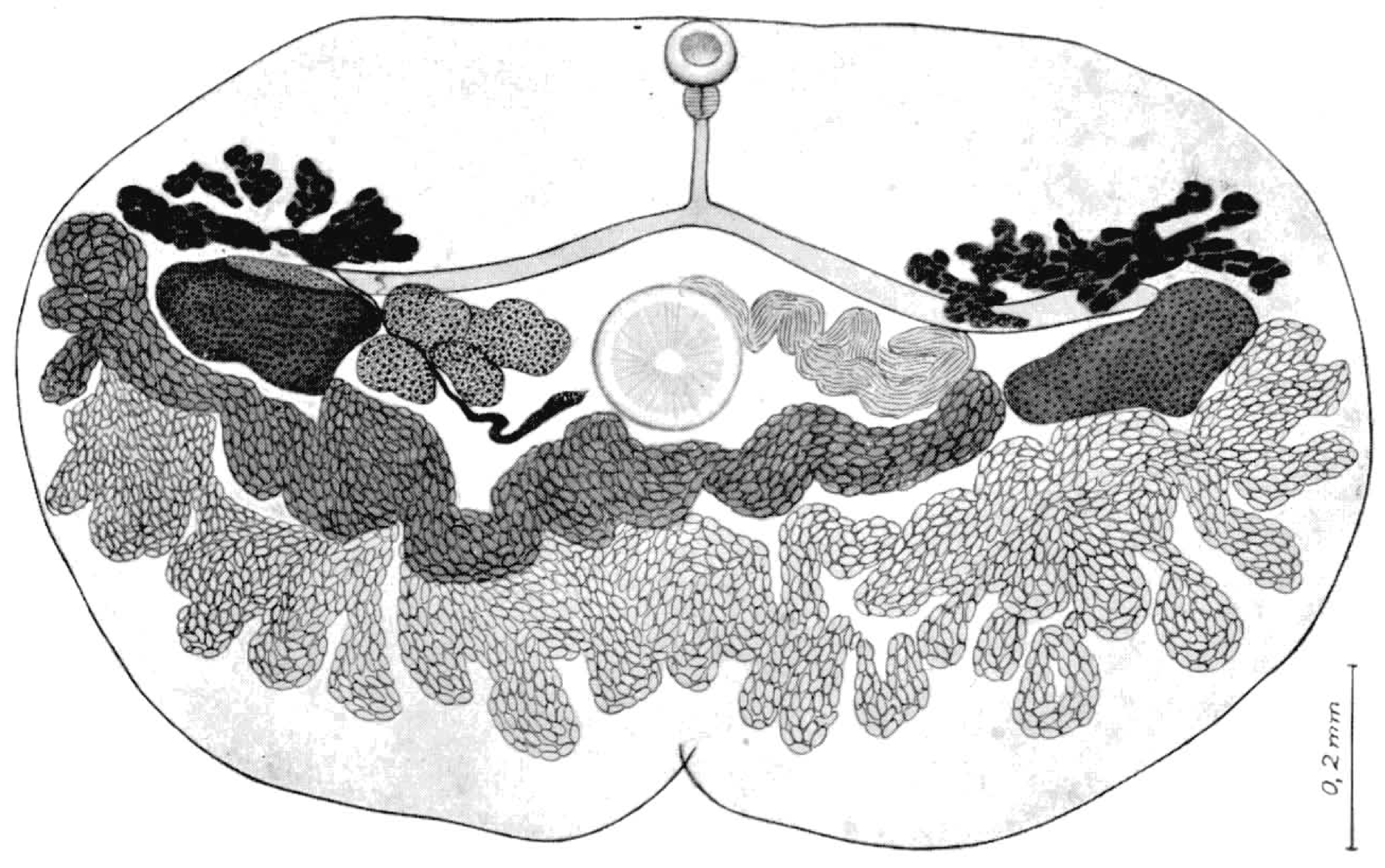

Fig. 7 


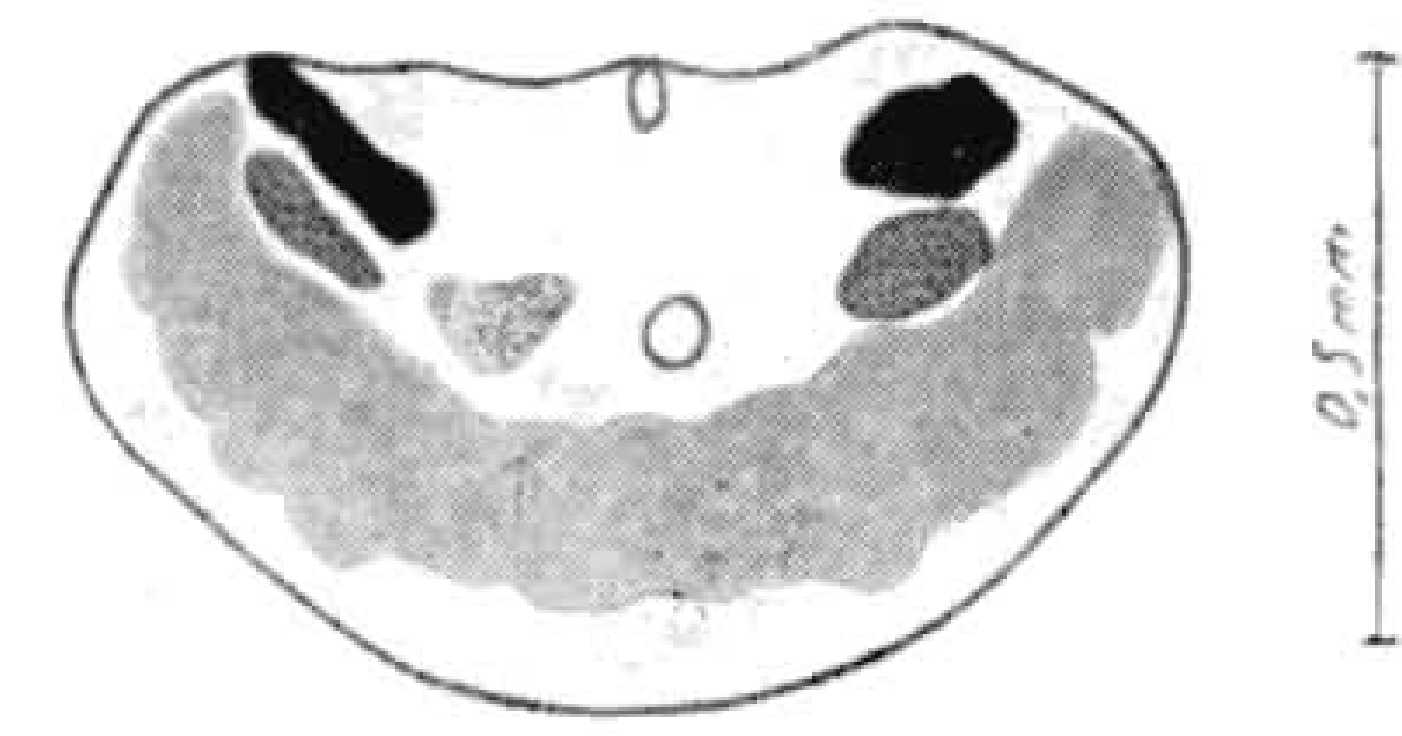

Fig. 1

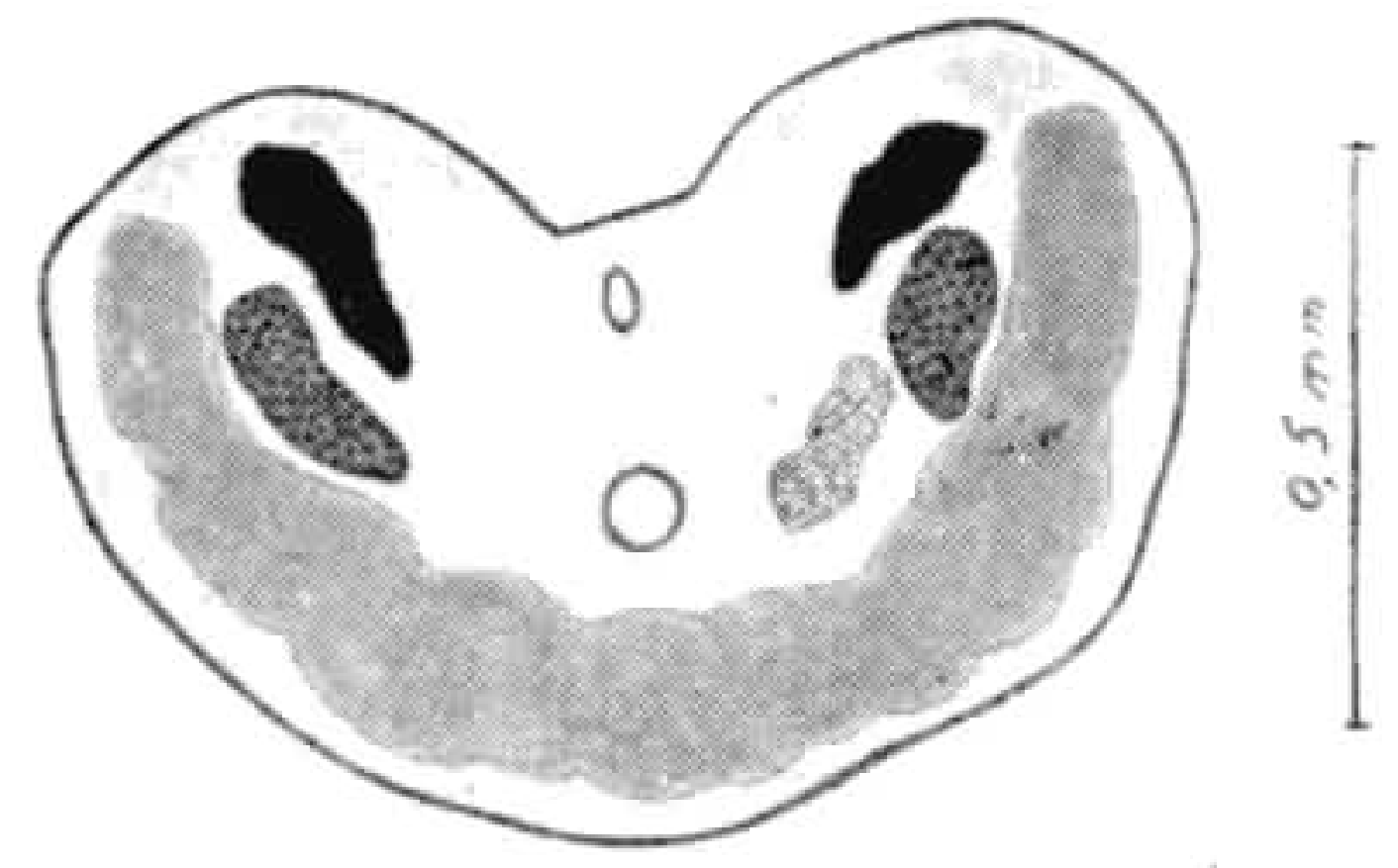

Fig. 2

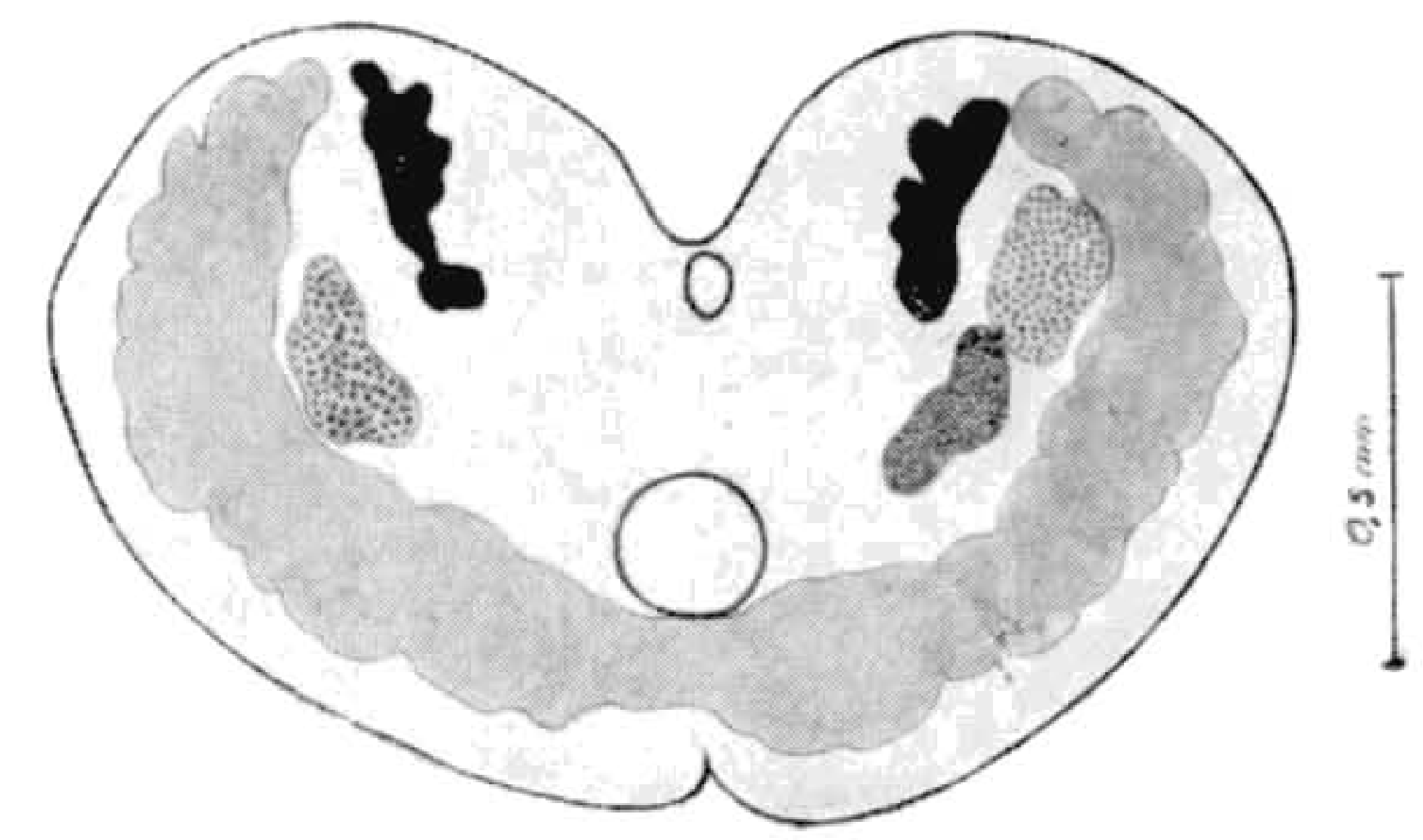

Fig. 5
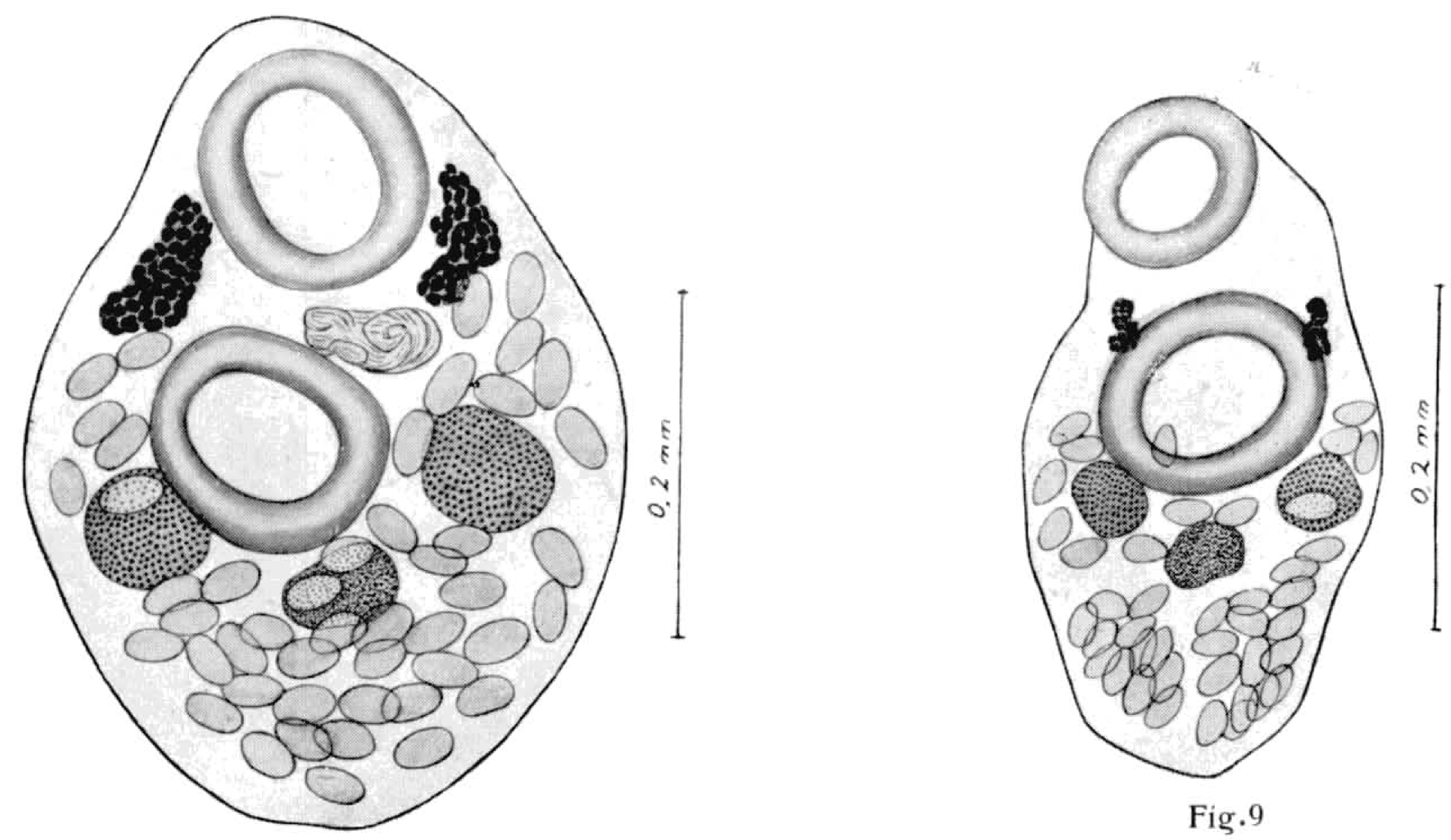

Fig. 8 